\title{
Editor's Remarks
}

The guest editors for this special issue, Jane Whynot, Sebastian Lemire, and Steve Montague, bring to our attention the continued importance of program theory. As they mention in their introduction, program theory is certainly not new to the field of evaluation; however, as our collective experiences continue to expand our understanding of program theorizing, we must take stock of what is known and what we need to develop further to meet the needs of organizations and stakeholders. Through practical examples and in-depth analyses, the papers included in this collection help us move beyond descriptions of program theory and consider instead how program theorizing can be conducted successfully in increasingly complex structures. I am pleased to introduce this special issue and thank the guest editors and authors for their contributions to the CJPE.

Isabelle Bourgeois

Editor-in-Chief 